\title{
Hepatoprotective effect of calculus bovis sativus on nonalcoholic fatty liver disease in mice by inhibiting oxidative stress and apoptosis of hepatocytes
}

This article was published in the following Dove Press journal:

Drug Design, Development and Therapy

\author{
Wenxi $\mathrm{He}^{1}$ \\ Yanjiao $X u^{\prime}$ \\ Chengliang Zhang' \\ Jingli Lu \\ Juan $\mathrm{Li}^{\prime}$ \\ Dong Xiang' \\ Jinyu Yang' \\ Mujun Chang ${ }^{3}$ \\ Dong Liu' \\ 'Department of Pharmacy, Tongji \\ Hospital, Tongji Medical College, \\ Huazhong University of Science and \\ Technology, Wuhan, Hubei, China; \\ ${ }^{2}$ Department of Pharmacy, The First \\ Affiliated Hospital of Zhengzhou \\ University, Zhengzhou, Henan, China \\ ${ }^{3}$ Center for Translational Medicine, \\ Tongji Hospital, Tongji Medical \\ College, Huazhong University of \\ Science and Technology, Wuhan, \\ Hubei, China
}

Correspondence: Dong Liu Department of Pharmacy, Tongji Hospital, Tongji Medical College, Huazhong University of Science and Technology, 1095 Jiefang Avenue, Wuhan, Hubei 430030, China Tel/fax +862783663643

Email Id2069@outlook.com

\begin{abstract}
Calculus bovis (CB, niu-huang) is a high-class therapeutic drug that is often used in traditional Chinese medicine. $\mathrm{CB}$ helps to eliminate heat and toxic components, and prevents the accumulation of phlegm and blood stasis in the liver. In Asian countries, CB Sativus (CBS), an ideal substitute for natural $\mathrm{CB}$, is presently extensively used for long-term treatment of chronic liver diseases. The present study aimed to evaluate the effects and potential mechanism(s) of action of CBS on mice with fructose-induced nonalcoholic fatty liver disease (NAFLD). The NAFLD model was established in C57BL/6 mice by exclusively feeding fluids containing 30\% fructose for 8 consecutive weeks. After these 8 weeks, mice were given CBS ( $50 \mathrm{mg} / \mathrm{kg} / \mathrm{day}$ or $100 \mathrm{mg} / \mathrm{kg} /$ day) for 2 consecutive weeks. Treatment with CBS reversed the fructose-induced impaired glucose tolerance. Compared with the model group, in which mice received 8 weeks of high-fructose diet and 2 weeks of $0.5 \%$ sodium carboxymethyl cellulose, CBS treatment significantly decreased the levels of fasting serum glucose, fasting insulin, triglyceride, and total cholesterol, and increased levels of high-density lipoprotein-cholesterol. CBS treatment also significantly decreased the levels of triglyceride, total cholesterol, and free fatty acid in the liver. The activity of superoxide dismutase in the liver was increased after treatment with CBS, however, levels of malondialdehyde and reactive oxygen species decreased. Histopathological examination showed that liver steatosis and injury were significantly reduced in CBS-treated mice. The expression of fatty acid synthase, nuclear factor kappa-light-chain-enhancer of activated B cells, Cysteinyl aspartate-specific proteinase-3, and synonyms B-cell leukemia/ lymphoma-2 gene-associated X protein were downregulated after treatment with CBS, whereas the expression of nuclear factor erythroid-2-related factor 2 was upregulated. In conclusion, CBS treatment exerted therapeutic effects in the liver of mice with NAFLD, which may be associated with amelioration of metabolic disorders, enhanced antioxidant effects, and alleviation of apoptosis.
\end{abstract}

Keywords: antioxidant, fructose, lipid metabolism, liver

\section{Introduction}

Nonalcoholic fatty liver disease (NAFLD), a hepatic manifestation of metabolic syndrome, is the most common chronic liver disease worldwide, affecting roughly 1 billion individuals. ${ }^{1}$ Due to the increased rate of obesity, the prevalence of NAFLD is rapidly increasing. The main pathology of NAFLD is hepatic lipid accumulation, in the absence of alcohol abuse and viral hepatitis. In $\sim 25 \%$ of patients, NAFLD may develop into cirrhosis, and progress to liver failure or cancer. ${ }^{2}$

It has been well-established that the incidence of NAFLD is associated with a Western diet, especially with the increase in fructose intake. ${ }^{3}$ Various studies have 
shown that a high-fructose diet may cause metabolic phenotypes in both mice and human. ${ }^{4}$ The fructose intake is 2- to 3-fold higher in patients with nonalcoholic steatohepatitis (NASH) when compared with their body mass index-matched controls. ${ }^{3}$ In addition, replacement of sugar-containing beverages with non-caloric beverages reduced weight gain and fat accumulation in normal-weight children. ${ }^{5}$ Although a relationship between fructose and NAFLD has been determined, effective and safe therapeutics are still not available.

Within traditional Chinese medicines, the main characteristics of NAFLD are described as retention of phlegmatic dampness, stagnation of damp heat, phlegm accumulation with stagnant blood, and turbi damp obstruction in the viscus. ${ }^{6}$ A great variety of herbs or natural products have long been used to treat NAFLD, and some have been shown to have few adverse effects. ${ }^{7}$ For example, calculus bovis (CB) (niu-huang in Chinese, and Goo in Japanese), which originates from bovine gall bladder, bile duct, or hepatic duct calculi, has shown beneficial effects in liver disorders according to "Shennong Bencao Jing" and "Compendium of Materia Medica" composed hundreds of years ago. ${ }^{8,9}$ During long-term clinical usage, it has been demonstrated that $\mathrm{CB}$ can efficiently eliminate heat and toxic materials, and remove accumulation of phlegm and blood stasis in the liver. Due to the under-resourced status and the high costs of $\mathrm{CB}$, the China Food and Drug Administration has approved CB Sativus (CBS) as an ideal substitute for CB. CBS and natural $\mathrm{CB}$ are similar in characteristics, ingredients, contents, and therapeutic effects. ${ }^{10}$ Although the therapeutic effects of $\mathrm{CB}$ and CBS in the liver are well documented, the underlying mechanism of action has not yet been identified.
In this study, we established an NAFLD model using high levels of fructose in the drinking water, to examine the therapeutic effects of CBS and explore its potential mechanism of action. Our data showed that in the fructose-induced NAFLD model, CBS treatment modulated lipid- and glucose-related metabolic disorders. In addition, CBS treatment postponed the progression of hepatic lesions. Overall, all effects caused by CBS treatment were associated with decreased levels of lipogenesis, oxidative stress, and apoptosis of hepatocytes.

\section{Materials and methods}

\section{Reagents}

CBS (dissolved in $0.5 \%$ sodium carboxymethyl cellulose [CMC-Na]) was provided by Wuhan Jianmin Dapeng Pharmaceuticals Co., Ltd (Lot: 2016-05-16, Wuhan, China). Effective components in CBS were quantified by high-performance liquid chromatography-tandem mass spectrometry as described previously. ${ }^{8}$ As shown in Figure 1, CBS contained $61.13 \mathrm{mg} / \mathrm{g}$ taurine, $69.04 \mathrm{mg} / \mathrm{g}$ cholic acid (CA), $25.52 \mathrm{mg} / \mathrm{g}$ deoxycholic acid (DCA), $0.30 \mathrm{mg} / \mathrm{g}$ ursodeoxycholic acid (UDCA), $6.88 \mathrm{mg} / \mathrm{g}$ chenodeoxycholic acid (CDCA), $0.2 \mathrm{mg} / \mathrm{g}$ hyodeoxycholic acid, $14.36 \mathrm{mg} / \mathrm{g}$ taurocholic acid, $3.58 \mathrm{mg} / \mathrm{g}$ taurodeoxycholic acid, $0.3 \mathrm{mg} / \mathrm{g}$ tauroursodeoxycholic acid, $0.46 \mathrm{mg} / \mathrm{g}$ taurochenodeoxycholic acid, $10.23 \mathrm{mg} / \mathrm{g}$ glycocholic acid, $3.11 \mathrm{mg} / \mathrm{g}$ glycodeoxycholic acid, and $2.89 \mathrm{mg} / \mathrm{g}$ glycochenodeoxycholic acid. The content of bilirubin $(37.6 \%)$ was determined by ultravioletvisible spectroscopy, based on instructions published in the "Chinese Pharmacopoeia" (2015 version). The results showed that the CBS used in this study meets the quality requirements of the "Chinese Pharmacopoeia". ${ }^{11}$

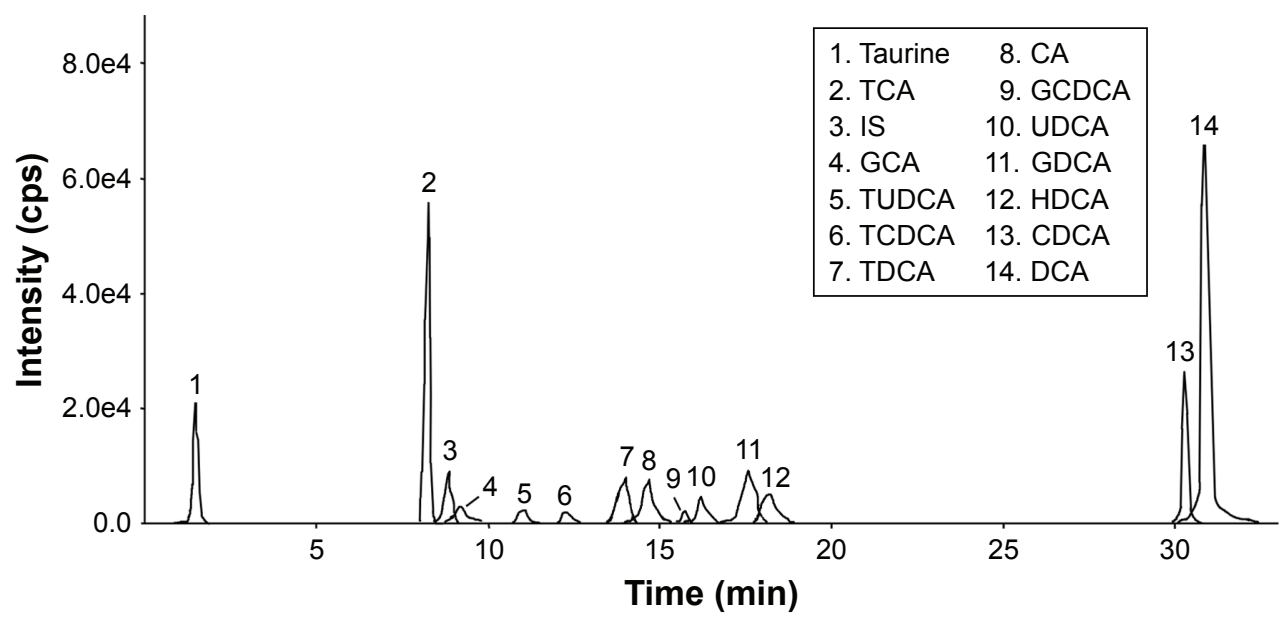

Figure I Multiple reaction monitoring (MRM) chromatogram of a representative sample of CBS.

Notes: The numbers represent peak sequence and identify which substance the peak represents.

Abbreviations: CA, cholic acid; CBS, calculus bovine sativus; CDCA, chenodeoxycholic acid; DCA, deoxycholic acid; GCA, glycocholic acid; GCDCA, glycochenodeoxycholic acid; GDCA, glycodeoxycholic acid; HDCA, hyodeoxycholic acid; IS, internal standard; TCA, taurocholic acid; TCDCA, taurochenodeoxycholic acid; TDCA, taurodeoxycholic acid; TUDCA, tauroursodeoxycholic acid; UDCA, ursodeoxycholic acid. 
Fructose was purchased from Tai Fenghai Pharmaceutical Co., Ltd., Jiangsu Province, China. Bicinchoninic acid protein assay kit was obtained from Beyotime Institute of Biotechnology, Shanghai, China. Insulin enzyme-linked immunosorbent assay (ELISA) kit was obtained from Westang Bio-Tech Co., Ltd, Shanghai, China. In addition, chemical reagent kits to identify low-density lipoprotein-cholesterol (LDL-C), highdensity lipoprotein-cholesterol (HDL-C), free fatty acid (FFA), total cholesterol (TC), triglyceride (TG), superoxide dismutase (SOD), malondialdehyde (MDA), and reactive oxygen species (ROS) were purchased from Nanjing Jiancheng Bioengineering Institute (Nanjing, China). Antibodies, including nuclear factor erythroid 2-related factor 2 (Nrf2), and synonyms B-cell leukemia/lymphoma-2 (Bcl-2) were purchased from R\&D systems (Minneapolis, MN, USA). Lamin B, $\beta$-actin, hormone-sensitive lipase (HSL), fatty acid synthase (FAS), nuclear factor kappa-light-chain-enhancer of activated B cells (NF-KB), Bcl-2-associated X protein (Bax), and Cysteinyl aspartate-specific proteinase-3 (Caspase-3) were purchased from Cell Signaling Technology (Beverly, MA, USA).

\section{Experimental animals}

Male C57BL/6 mice (4 weeks) were purchased from Hunan SJA Laboratory Animal Co., Ltd, Hunan, China, and housed in a specific pathogen-free environment. Animal care and experimental procedures were performed in strict accordance with the National Institutes of Health Guide for the Care and Use of Laboratory Animals. Animal experiments were approved by the Ethical Committee on Animal Experimentation of Tongji Medical College, Huazhong University of Science and Technology, Wuhan, China. The animal ethics number is TJ-A20141111.

\section{NAFLD model and drug intervention}

After a week of acclimation, the mice were randomly divided into groups and were fed either a normal diet with distilled water (control group, $\mathrm{n}=8$ ), or a high-fructose diet using a $30 \%$ fructose solution $(n=24) .{ }^{9}$ After being on the diet for 8 weeks, the mice that received a high-fructose diet were subdivided into 3 groups, and were intragastrically administered CBS (50 mg/kg/day) (CBS 50, n=8), CBS (100 mg/kg/day) (CBS 100, $\mathrm{n}=8$ ), or $0.5 \%$ CMC-Na (the co-solvent of CBS, $0.1 \mathrm{mg} / 10 \mathrm{~g}$ ) (model group, $\mathrm{n}=8$ ). Treatments were given once a day for 2 consecutive weeks.

\section{Body and liver weights}

Body weights were recorded weekly throughout the experiment. Before being sacrificed, the mice were kept fasting for
$12 \mathrm{~h}$ after the last dose of treatment. Then, the livers were removed, weighed, and stored at $-80^{\circ} \mathrm{C}$ until use.

\section{Oral glucose tolerance test (OGTT)}

After the last dose of agents and overnight fasting, an OGTT was performed. Each mouse was given an oral dose of $2 \mathrm{~g} / \mathrm{kg}$ body weight of D-glucose. At 0, 30, 60, 90, and $120 \mathrm{~min}$ after D-glucose administration, blood samples $(5 \mu \mathrm{L})$ were obtained from the caudal vein. Blood glucose levels were determined by using a blood glucose meter (ACCU-CHEK Performa, Roche, Germany).

\section{Metabolic parameters}

The mice were fasted for $12 \mathrm{~h}$ after 8 weeks of high-fructose feeding and 2 weeks of therapy. Then, blood glucose was measured, and serum was obtained by centrifugation of whole blood at 3,000 rpm for $15 \mathrm{~min}$ at $4{ }^{\circ} \mathrm{C}$.

ELISAs were performed to determine serum levels of insulin according to the manufacturer's instructions.

The homeostasis model for assessment of insulin resistance (HOMA-IR) was calculated using the relationship between fasting plasma glucose (FPG) and fasting serum insulin (FINS) levels according to the following formula: ${ }^{12}$

$$
\text { HOMA-IR }=\text { FPG }(\mathrm{mmol} / \mathrm{L}) \times \text { FINS }(\mathrm{mU} / \mathrm{L}) / 22.5 .
$$

\section{Lipid metabolism and oxidative stress}

Serum levels of LDL-C, HDL-C, TC, and TG were determined using chemical reagent kits and a spectrophotometric system (SYNGENE; Bio Tek, Madison, WI, USA). All experiments were conducted according to the manufacturer's instructions.

Approximately $0.1 \mathrm{~g}$ of dissected liver was added to 9 times the liver volume of phosphate buffered saline solution. After mechanical trituration at $4^{\circ} \mathrm{C}$, the mixture was centrifuged at $2,500 \mathrm{rpm}$ for $10 \mathrm{~min}$ at $4^{\circ} \mathrm{C}$. The supernatant was collected and levels of FFA, TC, TG, SOD, MDA, and ROS were determined according to the manufacturer's instructions.

\section{Histological evaluation of the liver}

The liver was cut into $4 \mu \mathrm{m}$ frozen sections and stored at $-20^{\circ} \mathrm{C}$. Next, the sections were fixed in $4 \%$ paraformaldehyde for $30 \mathrm{~min}$ at room temperature, stained with $0.3 \%$ oil red $\mathrm{O}$ solution for $30 \mathrm{~min}$, counter-stained with hematoxylin and eosin (H\&E) for $30 \mathrm{~s}$, and sealed with glycerin. Liver lipid accumulation was evaluated using an optical microscope $(200 \times)$. 
In addition, liver tissues were fixed in 4\% paraformaldehyde for 12-24 h, dehydrated in absolute ethanol, transparentized in dimethylbenzene, embedded in paraffin, sectioned into $4 \mu \mathrm{m}$ sections, deparaffinized, dehydrated with gradient ethanol solutions, routinely stained with H\&E, and sealed with optical resin. Pathological changes of the liver tissues were observed using an optical microscope (200×).

Using POD kit (Roche, Basel, Switzerland), terminal deoxynucleotidyl transferase dUTP nick end labeling (TUNEL) staining was conducted according to the manufacturer's guidelines. Hepatocytes that showed a positive TUNEL staining were observed using an optical microscope $(200 \times)$. In each section, 5 random fields were selected and the number of apoptotic cells per field was counted using Image-Pro Plus 5.1 software (Media Cybernetics, Rockville, MD, USA).

\section{Western blot analysis}

Total protein was isolated from the liver tissue using a commercial protein isolation kit (T-PER ${ }^{\circledR}$, Lot: QF217759, Thermo Fisher Scientific, Waltham, MA, USA) according to the manufacturer's instructions. Nuclear protein was extracted from the liver tissue using nuclear and cytoplasmic protein extraction kit (P0027; Beyotime, Shanghai, China). Proteins $(30 \mu \mathrm{g})$ were separated on $8 \%-12 \%$ sodium dodecyl sulfate polyacrylamide gel electrophoresis, and transferred to polyvinylidene fluoride membranes (Roche Diagnostics $\mathrm{GmbH}$, Mannheim, Germany). After blocking in 5\% nonfatty milk for an hour at room temperature, the membranes were incubated with primary antibodies directed against Nrf2, Bcl-2, HSL, FAS, NF-кB, Bax, and Caspase-3. After washing, the membranes were incubated with the appropriate secondary antibodies. The antibodies used were horseradish peroxidase (HRP)-conjugated goat anti-mouse in 5\% bovine serum albumin (BSA) for Nrf2 and Bcl-2 and HRP-conjugated goat anti-rabbit in 5\% BSA for HSL, FAS, NF-кB, Bcl-2, Bax, and Caspase-3. The membranes were then exposed to electrochemiluminescence reagent (Multi Sciences, Hangzhuo, China) for visualization of the proteins. The emitted light was captured by BOX Chemi XRQ imaging system (SynGene, Cambridge, UK), and the proteins were analyzed by Gene Tools Software Version 08-3d.3 (SynGene).

\section{Statistical analysis}

Data were expressed as the mean \pm SD. Significant differences between groups were assessed with GraphPad Prism 5 software (GraphPad Software, Inc., La Jolla, CA, USA). The differences between the means of groups were calculated by one-way analysis of variance (ANOVA), and repeated to measure ANOVA with least significant difference on post hoc analysis. Differences were considered statistically significant when $P<0.05$.

\section{Results}

\section{Body weight, liver weight, and liver index}

Basic physiological data are shown in Table 1. Mice in the model group had significantly increased body and liver weights $(P<0.001)$, as well as an increased liver index $(P<0.05)$. Treatment with CBS significantly decreased body and liver weights when compared with the model group $(P<0.01)$. In addition, CBS treatment slightly decreased the liver/body index; however, this difference was not significantly different.

\section{OGTT, fasting glucose level, fasting insulin level and HOMA-IR}

Results of the OGTT assay showed that intake of a high-fructose diet impaired glucose tolerance. This was indicated by the area under the curve for glucose, which was significantly increased in the model group $(P<0.05$, Figure 2$)$. Treatment with CBS $(50 \mathrm{mg} / \mathrm{kg})$ markedly reversed such impairment $(P<0.05$, Figure 2).

Fasting glucose and insulin levels, which were significantly higher in the model group compared with the control group, were significantly reduced after CBS treatment $(P<0.01)$. In our study, we used HOMA-IR to estimate the insulin resistance. As shown in Table 2, the intake of highfructose induced a substantial increase in insulin sensitivity. Moreover, treatment with CBS abolished fructose-induced HOMA-IR elevation. Overall, these results demonstrated that oral administration of CBS was effective in balancing highfructose-induced glucose metabolic disorders in mice.

Table I Effects of CBS on body weight, liver weight, and liver index of mice among 4 groups

\begin{tabular}{llll}
\hline Group & Body weight $(\mathrm{g})$ & Liver weight $(\mathrm{g})$ & Liver index \\
\hline Control & $21.63 \pm 1.76$ & $0.76 \pm 0.11$ & $0.034 \pm 0.003$ \\
Model & $30.45 \pm 3.02^{\mathrm{a}}$ & $1.28 \pm 0.45^{\mathrm{b}}$ & $0.043 \pm 0.006^{\mathrm{b}}$ \\
CBS $(50 \mathrm{mg} / \mathrm{kg})$ & $27.69 \pm 2.57^{* *}$ & $0.97 \pm 0.17^{*}$ & $0.040 \pm 0.008^{* *}$ \\
CBS $(100 \mathrm{mg} / \mathrm{kg})$ & $25.49 \pm 2.52^{* * *}$ & $0.82 \pm 0.14^{* *}$ & $0.037 \pm 0.003^{* *}$ \\
\hline
\end{tabular}

Notes: Control: non-NAFLD healthy mice; model: high-fructose-induced NAFLD mice; CBS (50 mg/kg): NAFLD mice treated with CBS at $50 \mathrm{mg} / \mathrm{kg}$ body weight; CBS $(100 \mathrm{mg} / \mathrm{kg})$ : NAFLD mice treated with CBS at $100 \mathrm{mg} / \mathrm{kg}$ body weight. Liver index = liver weight $(\mathrm{g}) /$ body weight $(\mathrm{g})$. Values are presented as the mean \pm SD of 8 mice per group. a $P<0.001$, vs the control group, ${ }^{b} P<0.01$, vs control group, ${ }^{*} P<0.05$, vs model group, $* * P<0.01$, vs model group, and $* * * P<0.001$, vs model group.

Abbreviations: CBS, calculus bovis sativus; NAFLD, nonalcoholic fatty liver disease. 
A

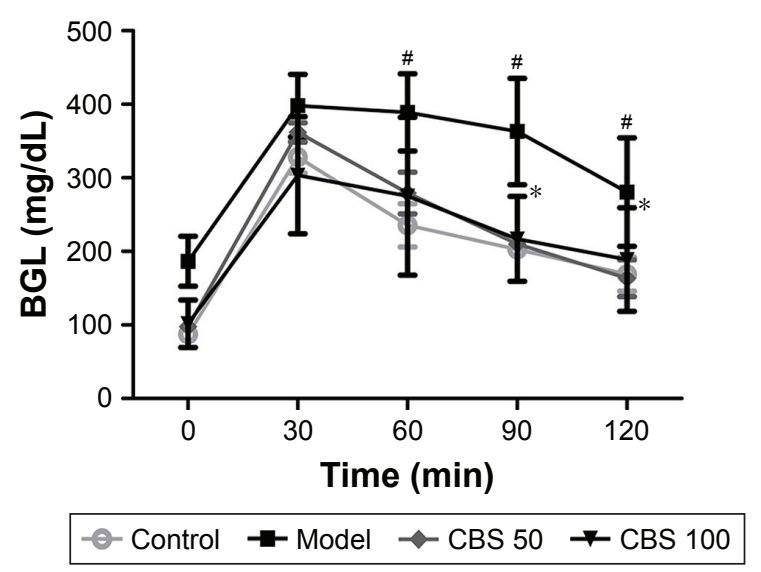

B

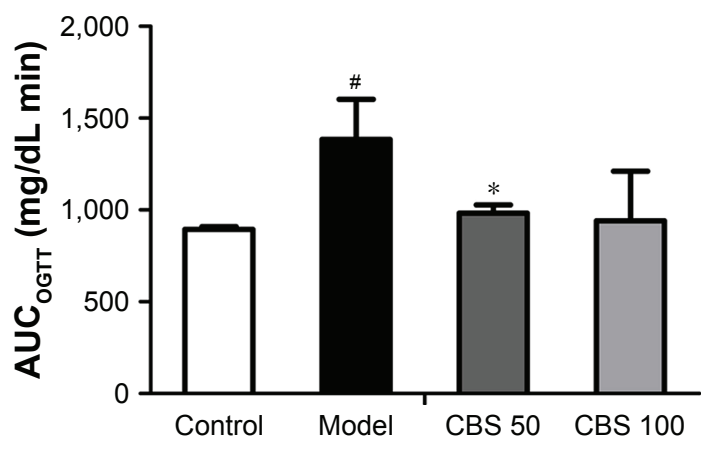

Figure 2 Effects of CBS (50 and $100 \mathrm{mg} / \mathrm{kg}$ ) on OGTT of NAFLD mice.

Notes: (A) Curve showing the change in blood glucose levels during OGTT. (B) Bar chart showing AUC of OGTT. Data are presented as the mean \pm SD of 3 mice per group. ${ }^{\#}<0.05$ vs the control group, ${ }^{*} P<0.05$ vs the model group. Control: non-NAFLD healthy mice; model: high-fructose induced NAFLD mice; CBS (50 mg/kg): NAFLD mice treated with CBS at $50 \mathrm{mg} / \mathrm{kg}$ body weight; CBS (100 mg/kg): NAFLD mice treated with CBS at $100 \mathrm{mg} / \mathrm{kg}$ body weight.

Abbreviations: AUC, area under the curve; BGL, blood glucose level; CBS, calculus bovis sativus; NAFLD, nonalcoholic fatty liver disease; OGTT, oral glucose tolerance test.

\section{Histopathological examination}

Histological evaluation provided direct evidence of the therapeutic effects of CBS treatment on high-fructose-induced NAFLD. In Oil Red O-stained sections, the liver cells in the control group had a normal structure, with a pale blue cytoplasm and without red lipid droplets. In liver cells of the model group, however, there were numerous uneven sized red lipid droplets, which indicated liver cell degeneration and lipid deposition. After CBS treatment, such degeneration was significantly mitigated, and the appearance of red lipid droplets in the cytoplasm was significantly decreased (Figure 3).

In the H\&E-stained sections, the hepatocytes were intact, and had a clearly structured appearance in the control group. The liver cell cords were arranged in order, and liver cells were uniformly sized with distinct, visible cell nuclei without lipid droplet vacuoles. However, in liver tissue of mice in

Table 2 Effects of CBS on FPG, FINS and HOMA-IR of mice among 4 groups

\begin{tabular}{llll}
\hline Group & $\begin{array}{l}\text { FPG } \\
(\mathbf{m m o l} / \mathbf{L})\end{array}$ & $\begin{array}{l}\text { FINS } \\
(\mathbf{m g} / \mathrm{L})\end{array}$ & HOMA-IR \\
\hline Control & $4.10 \pm 0.57$ & $9.50 \pm 1.24$ & $1.72 \pm 1.12$ \\
Model & $8.90 \pm 0.86^{\mathrm{a}}$ & $22.50 \pm 2.88^{\mathrm{b}}$ & $8.85 \pm 1.62^{\mathrm{a}}$ \\
CBS $(50 \mathrm{mg} / \mathrm{kg})$ & $6.48 \pm 1.29^{* * *}$ & $13.12 \pm 2.42^{* *}$ & $3.63 \pm 1.21^{* * *}$ \\
CBS $(100 \mathrm{mg} / \mathrm{kg})$ & $5.42 \pm 0.57^{* * *}$ & $10.31 \pm 1.96^{* *}$ & $2.48 \pm 1.11^{* * *}$ \\
\hline
\end{tabular}

Notes: Control: non-NAFLD healthy mice; model: high-fructose induced NAFLD mice; CBS (50 mg/kg): NAFLD mice treated with CBS at $50 \mathrm{mg} / \mathrm{kg}$ body weight; CBS $(100 \mathrm{mg} / \mathrm{kg})$ : NAFLD mice treated with CBS at $100 \mathrm{mg} / \mathrm{kg}$ body weight. Liver index = liver weight $(\mathrm{g}) /$ body weight $(\mathrm{g})$. Values are presented as the mean \pm SD of 8 mice per group. a $P<0.001$, vs the control group, ${ }^{\text {b }} P<0.01$, vs control group, $* * P<0.0$ I, vs model group, and $* * * P<0.001$, vs model group.

Abbreviations: CBS, calculus bovis sativus; FPG, fasting plasma glucose; FINS, fasting serum insulin; HOMA-IR, homeostasis model assessment of insulin resistance; NAFLD, nonalcoholic fatty liver disease. the model group, large areas of fatty degeneration were found, showing diffusive, uneven-sized round lipid droplets. Moreover, cell nuclei did not appear in the center of the cell, but were pushed to the side. After CBS treatment, fatty degeneration was significantly reduced compared with that of the model group, and pathological structures were roughly identical to those in the control group (Figure 3). These results suggested that the oral administration of CBS was effective in treating high-fructose-induced fatty liver. Furthermore, CBS treatment had therapeutic effects on the physiological structure of high-fructose-induced hepatocyte damage.

\section{Hepatic biochemical indices}

In the fructose-induced NAFLD model group, hepatic levels of TG, TC, and FFA were significantly increased, whereas these biochemical indices were significantly reduced in a dose-dependent manner by CBS treatment (50 and $100 \mathrm{mg} / \mathrm{kg})(P<0.05$, Figure 4). These results supported the histopathological findings.

\section{Biochemical indices in serum}

Serum levels of TG, TC, and LDL-C in the model group significantly exceeded those of the control group. TG and TC levels were significantly reduced by CBS treatment, whereas LDL-C levels did not change $(P<0.05$, Figure 5$)$. Serum HDL-C levels were significantly increased after CBS treatment $(P<0.05$, Figure 5$)$. These data, together with the histopathological findings and hepatic biochemical indices, indicated that orally administered CBS was effective in improving lipid metabolism. 

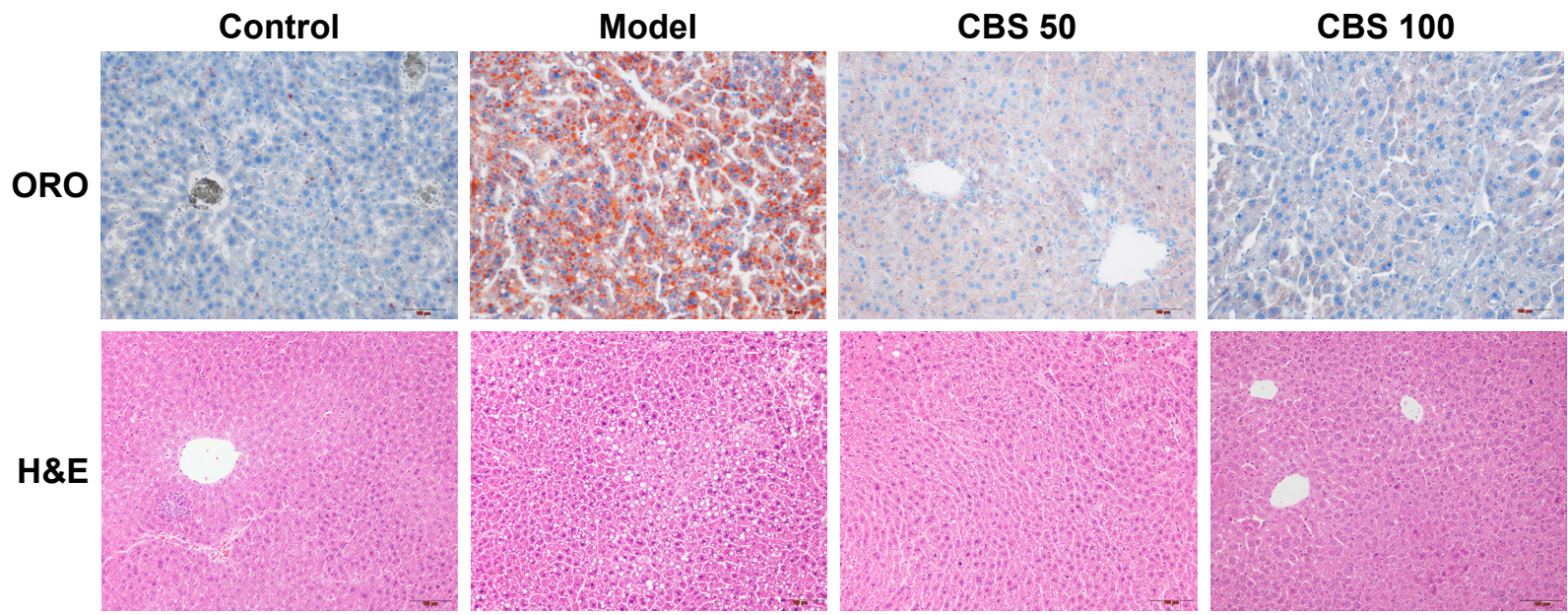

Figure 3 ORO and H\&E staining of mouse livers.

Notes: Effects of CBS (50 and $100 \mathrm{mg} / \mathrm{kg}$ ) on fructose-induced lipid accumulation and macrovesicular steatosis. Images were captured at $200 \times$ magnification. Control: nonNAFLD healthy mice; model: high-fructose induced NAFLD mice; CBS (50 mg/kg): NAFLD mice treated with CBS at 50 mg/kg body weight; CBS (I00 mg/kg): NAFLD mice treated with CBS at $100 \mathrm{mg} / \mathrm{kg}$ body weight.

Abbreviations: CBS, calculus bovis sativus; H\&E, hematoxylin and eosin; NAFLD, nonalcoholic fatty liver disease; ORO, Oil-Red-O.

\section{Effects on hepatic lipogenesis and lipolysis}

To determine the effect of CBS treatment on the cause of glucose and lipid disorder, main metabolic enzymes (FAS and HSL) were evaluated. Fructose feeding increased FAS expression levels, and when compared with the model group, this elevation was found to be normal after treatment with CBS $(P<0.05$, Figure 6). However, treatment with CBS did not affect expression levels of HSL. These results demonstrated that oral administration of CBS reduced fatty liver by downregulating the expression of FAS.

\section{Oxidative stress markers in liver homogenate}

As shown in Figure $7 \mathrm{~A}-\mathrm{C}$, indices of oxidative stress, such as SOD, MDA and ROS were determined. In the model group, hepatic levels of MDA and ROS were found to be significantly higher compared with that of the control group, and treatment with CBS significantly decreased MDA and ROS levels compared with that of the model group $(P<0.05$, Figure 7). We also found that the hepatic SOD activity of mice in the model group was significantly lower compared with that of the control group. In addition, treatment with CBS significantly increased SOD enzyme's activity $(P<0.05$, Figure 7). Together, these results demonstrated that oral administration of CBS was effective in ameliorating highfructose-induced lipid peroxidation in the liver.

\section{Effects on hepatic nuclear Nrf2 expression}

To further study the antioxidant ability of CBS, we examined the expression of the nuclear Nrf2 protein in high-fructoseinduced fatty liver. We found that, compared with the control group, a high-fructose diet decreased nuclear $\mathrm{Nrf2}$ expression
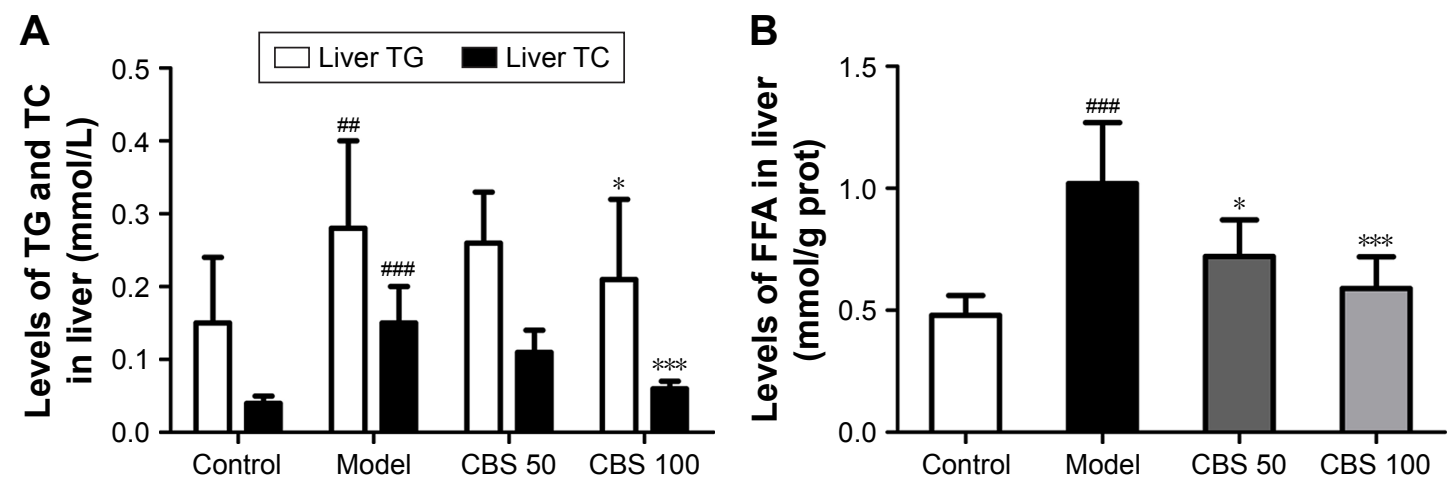

Figure 4 Effects of CBS (50 and $100 \mathrm{mg} / \mathrm{kg}$ ) on TG and TC (A) and FFA (B) of NAFLD mice.

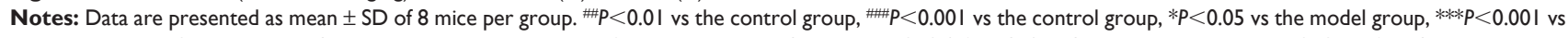
the model group. Control: non-NAFLD healthy mice; model: high-fructose induced NAFLD mice; CBS (50 mg/kg): NAFLD mice treated with CBS at 50 mg/kg body weight; CBS (100 mg/kg): NAFLD mice treated with CBS at $100 \mathrm{mg} / \mathrm{kg}$ body weight.

Abbreviations: CBS, calculus bovis sativus; FFA, free fatty acid; NAFLD, nonalcoholic fatty liver disease; prot, protein; TC, total cholesterol; TG, triglyceride. 

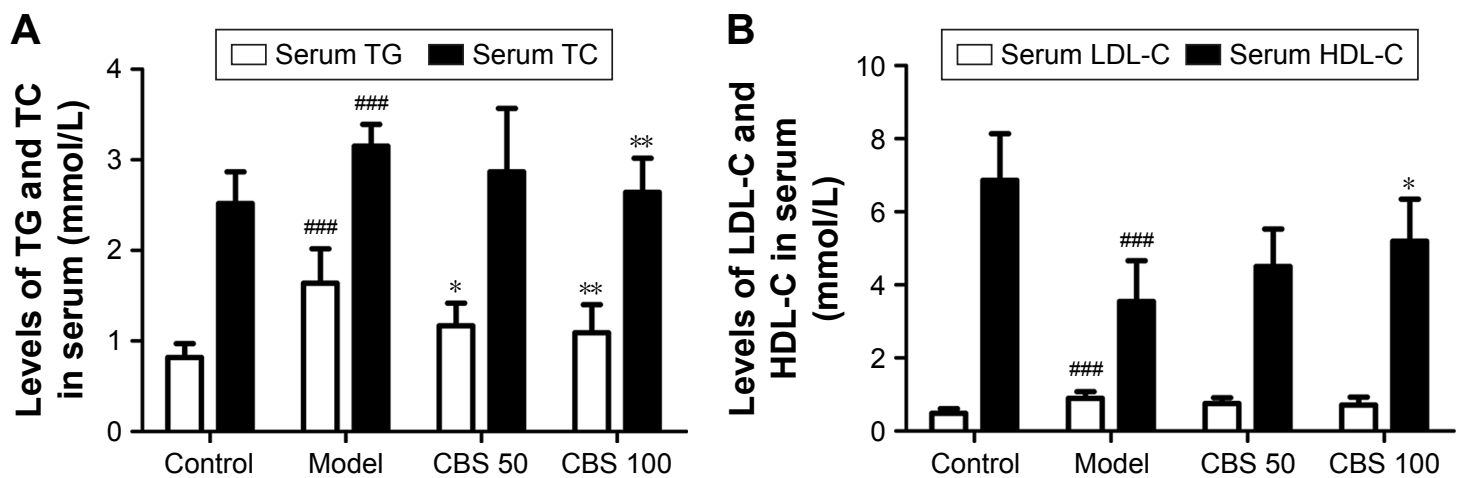

Figure 5 Effects of CBS (50 and $100 \mathrm{mg} / \mathrm{kg}$ ) on TG and TC (A), LDL-C and HDL-C (B).

Notes: Data are presented as mean \pm SD of 8 mice per group. ${ }^{\# P} P 0.001$ vs the control group, $* P<0.05$ vs the model group, ${ }^{* *} P<0.01$ vs the model group. Control: nonNAFLD healthy mice; model: high-fructose induced NAFLD mice; CBS (50 mg/kg): NAFLD mice treated with CBS at 50 mg/kg body weight; CBS (I00 mg/kg): NAFLD mice treated with CBS at $100 \mathrm{mg} / \mathrm{kg}$ body weight.

Abbreviations: CBS, calculus bovis sativus; HDL-C, high density lipoprotein-cholesterol; LDL-C, low density lipoprotein-cholesterol; NAFLD, nonalcoholic fatty liver disease; TG, triglyceride; TC, total cholesterol.

levels and this alteration normalized after treatment with CBS (mainly $100 \mathrm{mg} / \mathrm{kg})$ compared with the model group $(P<0.01$, Figure 8). These results indicated that oral administration of CBS activated the expression of nuclear Nrf2, which contributed to the protection of hepatocytes from oxidative damage.

\section{Effects on high-fructose-induced apoptosis}

Lipid peroxidation produces excessive levels of ROS, which can trigger hepatocyte apoptosis..$^{13}$ The number of apoptotic cells in the model group was found to be significantly higher compared with that of the control group. Moreover, CBS treatment ameliorated apoptosis of hepatocytes. Compared with the control group, a high-fructose diet increased the levels of Caspase-3, Bax, and nuclear NF-кB. Moreover,

A
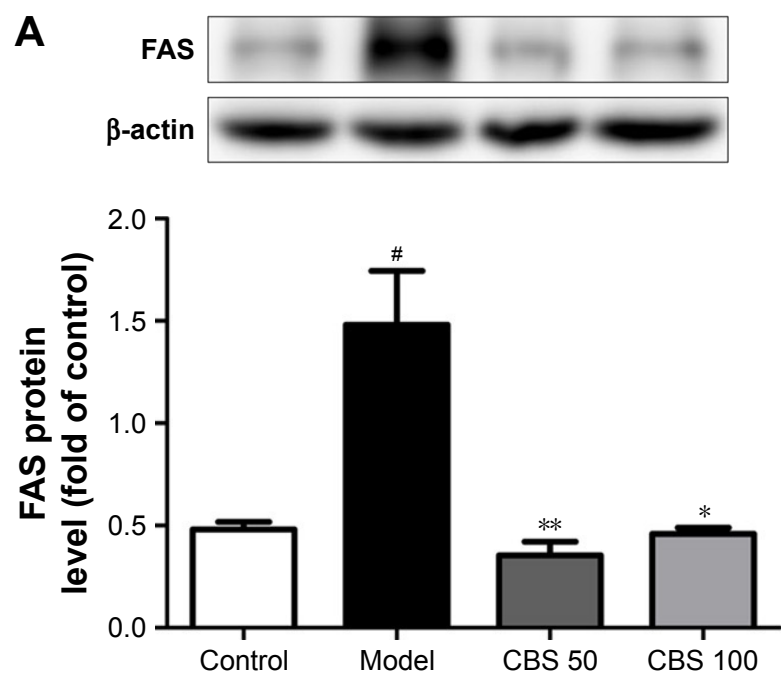

administration of CBS significantly decreased nuclear NF- $\kappa \mathrm{B}$, Caspase-3, and Bax levels $(P<0.05$, Figure 9); however, expression of Bcl-2 was not affected. These results suggested that oral administration of CBS was effective in regulating high-fructose-induced hepatocyte apoptosis.

\section{Discussion}

High-fructose-induced NAFLD mice have symptoms, such as lipid accumulation, insulin resistance, and oxidative damage, which resemble the characteristics of NAFLD observed in humans..$^{14}$ In addition, the pathogenesis of NAFLD is in accordance with the newly promoted "multiple parallel hits" hypothesis of NAFLD. ${ }^{15}$ In this model, due to its unique metabolic pathway, fructose leads to rapid hepatic de novo lipogenesis (DNL), which bypasses the rate-limiting enzyme

B

HSL
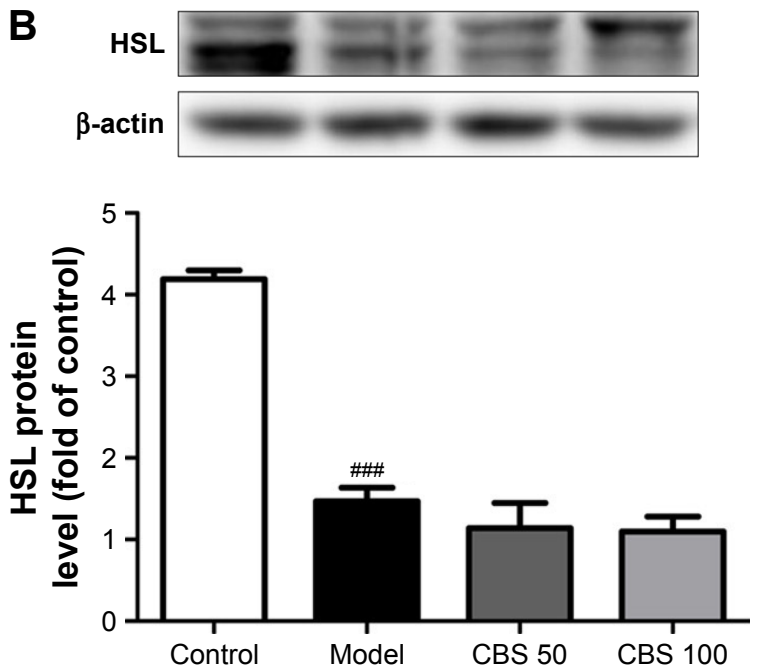

Figure 6 Effects of CBS (50 and $100 \mathrm{mg} / \mathrm{kg}$ ) on the protein expression levels of FAS (A) and HSL (B).

Notes: Data are presented as mean \pm SD of 3 mice per group. ${ }^{\#}<0.05$ vs the control group, ${ }^{\#} P<0.00$ I vs the control group, ${ }^{*} P<0.05$ vs the model group, ${ }^{* *} P<0.01$ vs the model group. Control: non-NAFLD healthy mice; model: high-fructose induced NAFLD mice; CBS (50 mg/kg): NAFLD mice treated with CBS at 50 mg/kg body weight; CBS (100 mg/kg): NAFLD mice treated with CBS at $100 \mathrm{mg} / \mathrm{kg}$ body weight.

Abbreviations: CBS, calculus bovis sativus; FAS, fatty acid synthase; HSL, hormone-sensitive lipase; NAFLD, nonalcoholic fatty liver disease. 

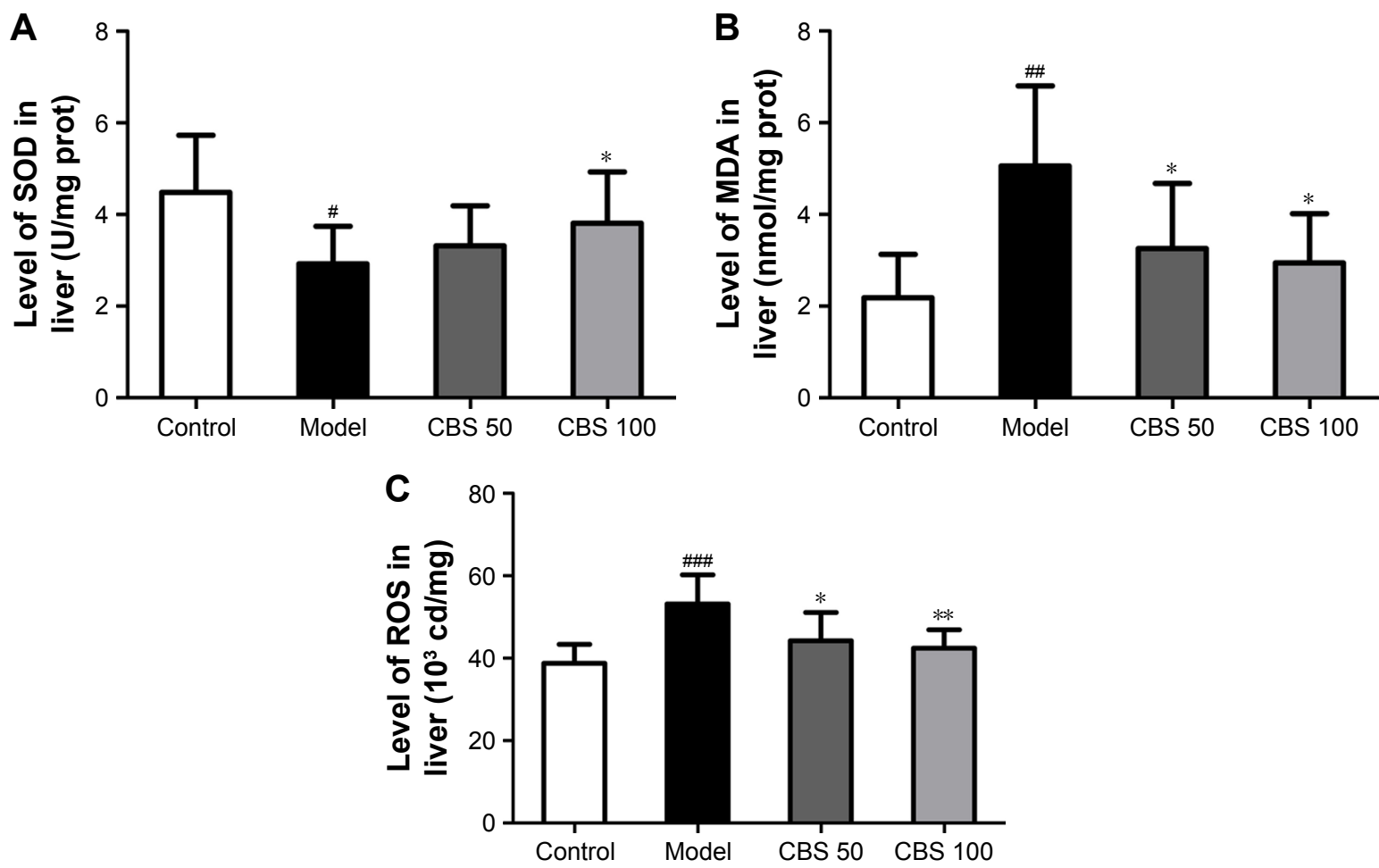

Figure 7 Effects of CBS (50 and $100 \mathrm{mg} / \mathrm{kg}$ ) on SOD (A), MDA (B), and ROS (C) of NAFLD mice.

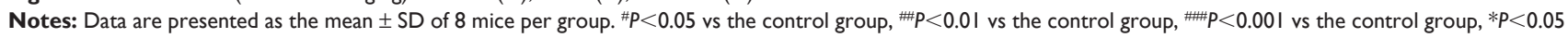
vs the model group, $* * P<0.01$ vs the model group. Control: non-NAFLD healthy mice; model: high-fructose induced NAFLD mice; CBS ( 50 mg/kg): NAFLD mice treated with CBS at $50 \mathrm{mg} / \mathrm{kg}$ body weight; CBS (100 mg/kg): NAFLD mice treated with CBS at $100 \mathrm{mg} / \mathrm{kg}$ body weight.

Abbreviations: CBS, calculus bovis sativus; MDA, malondialdehyde; NAFLD, nonalcoholic fatty liver disease; prot, protein; ROS, reactive oxygen species; SOD, superoxide dismutase.

phosphofructokinase. ${ }^{16}$ Moreover, the steatosis that is caused by excessive fructose intake increases the sensitivity of the liver to, for example, oxidative stress and insulin resistance (IR), which leads to hepatocyte damage and liver dysfunction. ${ }^{16,17}$

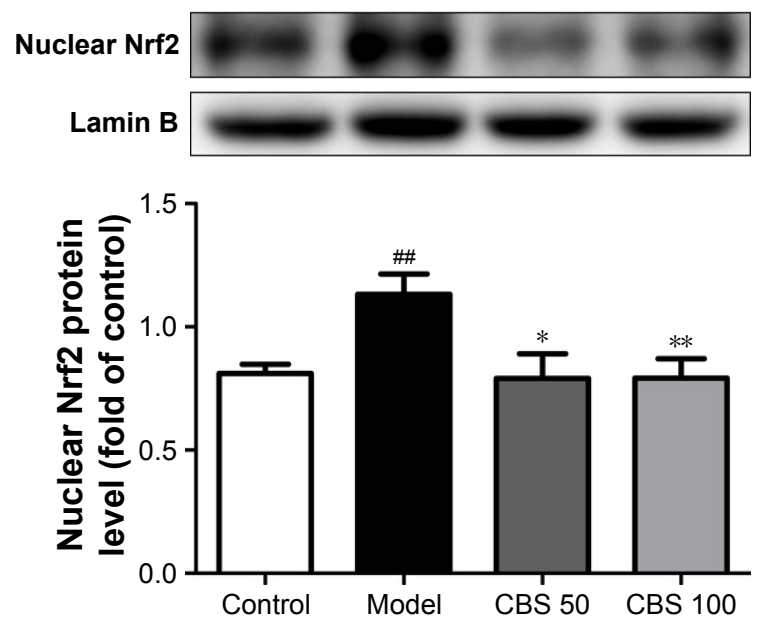

Figure 8 Effect of CBS (50 and $100 \mathrm{mg} / \mathrm{kg}$ ) on the protein expression level of Nrf2. Notes: Data are presented as the mean \pm SD of 3 mice per group. ${ }^{\#} P<0.01$ vs the control group, $* P<0.05$ vs the model group, ${ }^{* * P}<0.01$ vs the model group. Control: non-NAFLD healthy mice; model: high-fructose induced NAFLD mice; CBS (50 mg/ $\mathrm{kg}$ ): NAFLD mice treated with CBS at $50 \mathrm{mg} / \mathrm{kg}$ body weight; CBS (100 mg/kg): NAFLD mice treated with CBS at $100 \mathrm{mg} / \mathrm{kg}$ body weight.

Abbreviations: CBS, calculus bovis sativus; NAFLD, nonalcoholic fatty liver disease; Nrf2, nuclear factor erythroid-2 related factor 2 .
In this study, we investigated the effects of CBS treatment on $30 \%$ high-fructose-induced NAFLD in mice, and explored its potential mechanism of action. The body weight, liver/ body weight ratio, fasting blood glucose, and IR index were significantly increased by high-fructose intake $(P<0.05)$. We found that in NAFLD mice, TC and TG levels in serum and liver were significantly increased, whereas the HDL-C content in serum was significantly decreased $(P<0.05)$. In addition, the liver of mice in the model group contained numerous lipid droplets in the cytoplasm. The aforementioned results indicated that we successfully established an NAFLD model in mice.

At the early stages of NAFLD, lipids, especially TG, abnormally accumulate in the liver. As a result, lipid homeostasis is disturbed, and FFA is continuously transported to the liver. Intragastric administration of CBS significantly decreases the liver weight, lipid droplets in liver, and biomedical indices (TC, TG, and FFA) of serum and liver. Although the effect on serum LDL-C was minor, CBS treatment markedly elevated serum levels of HDL-C. In addition, CBS treatment reversed the impaired glucose tolerance that was induced by fructose. Finally, CBS treatment significantly decreased fasting serum glucose levels, serum insulin levels, and HOMA-IR. These 
A

A

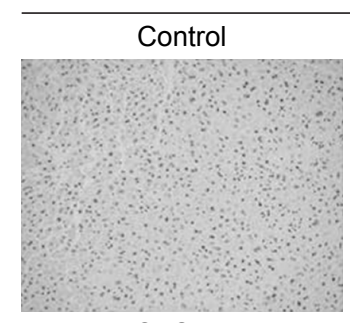

CBS 50

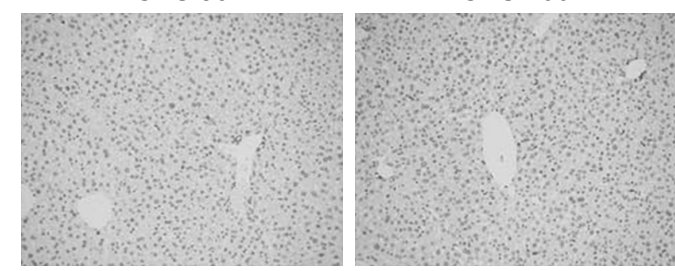

C
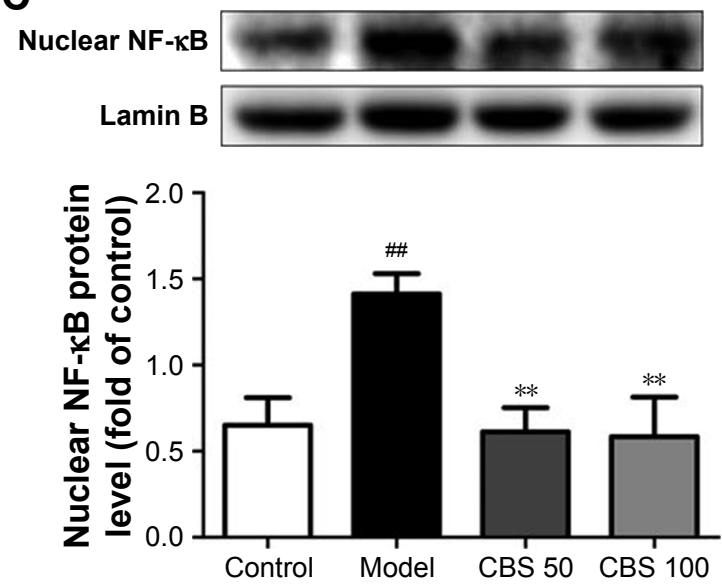

E
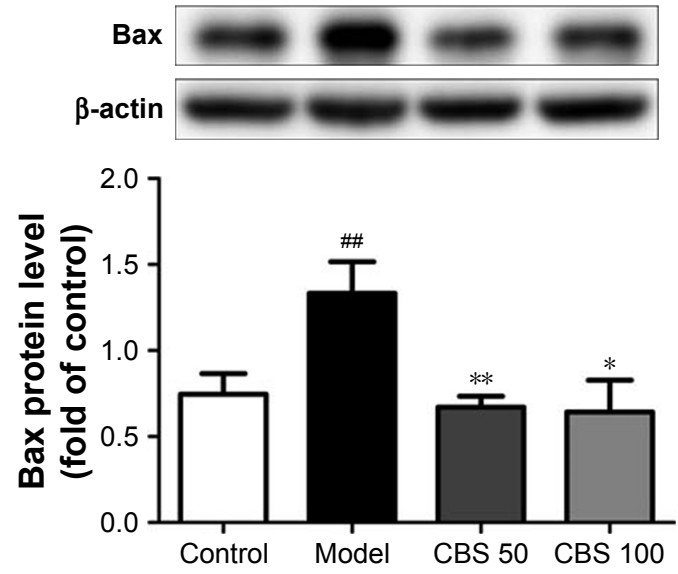

B

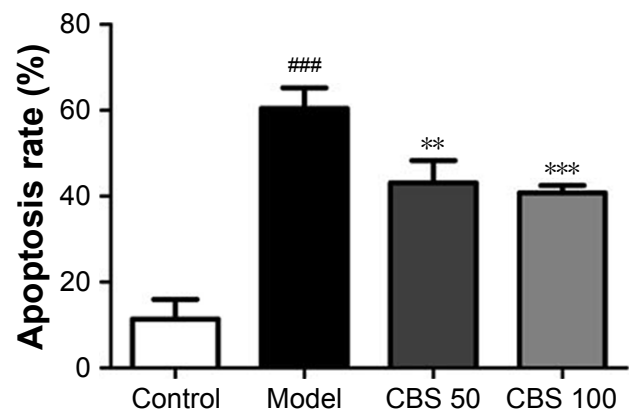

D
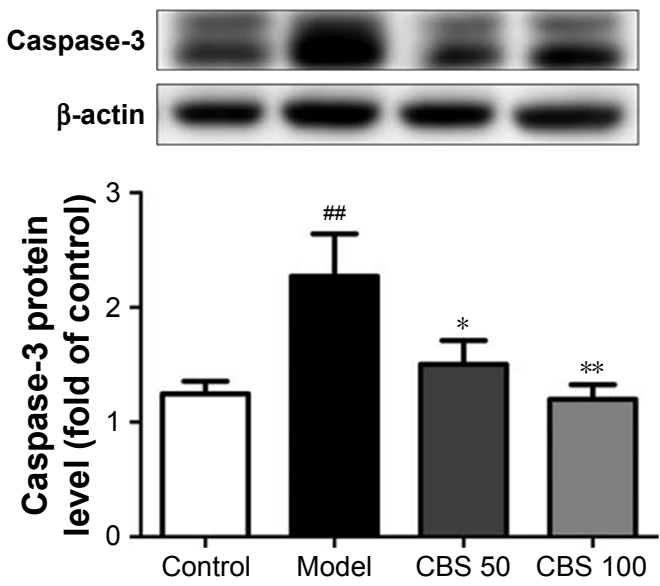

$\mathbf{F}$
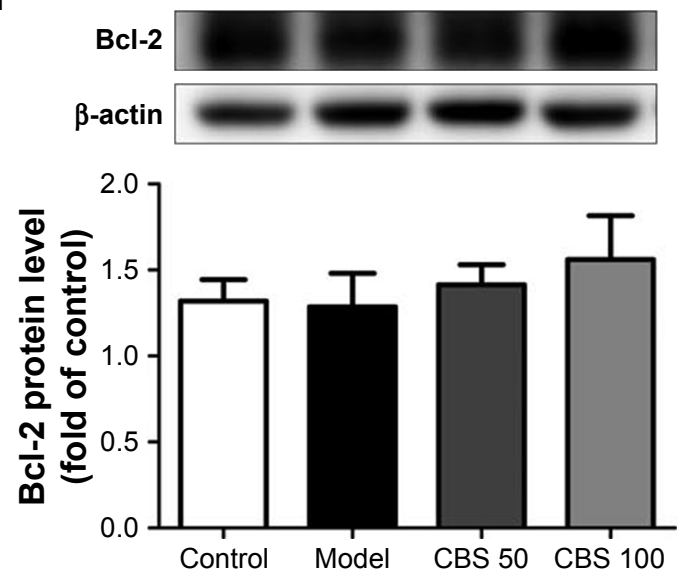

Figure 9 Effects of CBS (50 and $100 \mathrm{mg} / \mathrm{kg}$ ) on the hepatocyte apoptosis.

Notes: (A) TUNEL stain of liver tissue, (B) the percentages of apoptotic cells, (C) NF-KB, (D) Caspase-3, (E) Bax, and (F) Bcl-2. Data are presented as the mean \pm SD of 3 mice per group. ${ }^{\# P} P 0.01$ vs the control group, ${ }^{\#} P<0.001$ vs the control group, $* P<0.05$ vs the model group, $* * P<0.01$ vs the model group, ${ }^{* * *} P<0.00$ I vs the model group. Control: non-NAFLD healthy mice; model: high-fructose induced NAFLD mice; CBS ( $50 \mathrm{mg} / \mathrm{kg}$ ): NAFLD mice treated with CBS at $50 \mathrm{mg} / \mathrm{kg}$ body weight; CBS (I00 mg/kg): NAFLD mice treated with CBS at $100 \mathrm{mg} / \mathrm{kg}$ body weight.

Abbreviations: $\mathrm{Bax}, \mathrm{Bcl}-2$ associated $\mathrm{X}$ protein; $\mathrm{Bcl}-2$, B-cell leukemia/lymphoma-2; Caspase-3, cysteinyl aspartate specific proteinase-3; CBS, calculus bovis sativus; NAFLD, nonalcoholic fatty liver disease; NF- $\mathrm{BB}$, nuclear factor kappa-light-chain-enhancer of activated B cells; TUNEL, terminal deoxynucleotidyl transferase dUTP nick end labeling.

results indicate that CBS ameliorated NAFLD through correcting lipid and glucose metabolic disorders.

Fructose metabolism has many unique features. One of the most important is the ability of fructose to support enhanced hepatic DNL. ${ }^{18}$ Dietary fructose increases levels of enzymes involved in DNL more strongly when compared with a highfat diet. FAS is a multi-functional enzyme that catalyzes the synthesis of long-chain fatty acids from acetyl-CoA and 
malonyl-CoA. ${ }^{19}$ In mice, liver-specific FAS knockout did not cause noticeable metabolic disorders when mice were fed a regular chow diet. However, when challenged with a low-fat/high-carbohydrate diet, these mice developed hepatic steatosis. ${ }^{20}$ During fatty acid metabolism, both adipose triglyceride lipase (ATGL) and HSL are responsible for $>95 \%$ of TG hydrolysis. ATGL and HSL regulate basal lipolysis, whereas the stimulation of lipolysis is determined by HSL alone. The rate-limiting step in modulating complete lipolysis is determined by HSL, which catalyzes diacylglycerol and monoacylglycerol into FFAs. ${ }^{21} \mathrm{HSL}$ is also engaged in the mobilization of fatty acids from intracellular lipids stored in tissues. As key factors in the process of lipogenesis and lipolysis, the expressions of FAS and HSL are disturbed in NAFLD. ${ }^{22}$ Our results showed that a high-fructose diet upregulated the expression of FAS, and downregulated the expression of HSL. The alteration of FAS was reversed, whereas the HSL content did not change after treatment with CBS. Thus, the decrease in the expression of FAS by CBS treatment resulted in a decrease in DNL, leading to decreased hepatic steatosis.

Numerous experimental and human studies have reported that ROS markedly promote the transformation of fatty liver into NASH. ${ }^{23}$ Fructose is conducive to ROS formation, which is primarily due to the molecular instability of its 5-membered furanose ring. Excessive ROS generated by the overconsumption of fructose causes burden on quenching by hepatic antioxidants. ${ }^{16}$ In the current study, the amelioration of oxidative stress markers suggested an antioxidant effect of CBS treatment in high-fructose-induced NAFLD. Nrf2 plays a central role in expressing various antioxidant-related genes that are associated in the cellular defense against oxidative stress. ${ }^{24}$ In rodent models of dietinduced NASH, deletion of $\mathrm{Nrf} 2$ promotes the progression of steatosis to steatohepatitis and fibrosis. ${ }^{25}$ Administration of an Nrf2 activator significantly attenuated the progression of histologic abnormalities, especially hepatic fibrosis in rats that were fed a choline-deficient L-amino acid-defined diet. ${ }^{26}$ In high-fructose-induced NAFLD animals, oral administration of CBS reversed the downregulated nuclear Nrf2 expression, indicating that increased SOD activity and decreased MDA and ROS levels by CBS treatment may be relevant to the activation of the Nrf2 pathway, and ultimately contribute to the protection of hepatocytes from oxidative damage.

The anti-oxidative activity of CBS has been previously confirmed in other diseases, including intrahepatic cholestasis and hyperlipemia vascular dementia. ${ }^{27,28}$ In addition, the oxidation-resistance effect may be closely related to its material basis. Bilirubin (over $35.0 \%$ ) or bile acids, which are the main pharmaceutical ingredients of CBS, have been found to have the ability of scavenging free radicals. ${ }^{29}$ Bilirubin has well-proven physiological roles, including oxidation resistance as well as scavenging of ROS and free radicals. ${ }^{29}$ In addition, unconjugated bilirubin is known to be one of the most potent endogenous antioxidants. In an article published in Science, it was reported that in liposomes, under $2 \%$ oxygen, bilirubin suppresses the oxidation more than $\alpha$-tocopherol, which is regarded as the best antioxidant of lipid peroxidation. ${ }^{30,31}$ Several large population studies have demonstrated a negative correlation between serum bilirubin levels and the development of NAFLD. ${ }^{32,33}$ In addition, Hinds et al hypothesized that bilirubin, which is considered a novel selective peroxisome proliferator-activated receptor (PPAR) modulator, increases hepatic fatty acid metabolism through a PPAR $\alpha$-dependent mechanism, and reduces hepatic lipid accumulation and protects against NAFLD. ${ }^{34}$ Moreover, the components taurine and UDCA, which are present in CBS, have been confirmed to have antioxidant effects in NAFLD, and act by increasing hepatic glutathione levels and inhibiting hydrophobic bile salt-induced Kupffer cell activation. ${ }^{35,36}$ Collectively, these data imply that CBS may exert antioxidant effects that possibly rely on the synergism of its multiple ingredients, which ultimately contribute to the alleviation of NAFLD.

Apoptosis of hepatocytes has recently been described in patients with NASH. The presence of apoptosis in fatty liver might be attributed to lipid peroxide and ROS, generated from lipid and glucose in metabolic disorders. ${ }^{14}$ Ribeiro et al confirmed the prominent role of apoptosis in NASH patients. ${ }^{37}$ They further demonstrated that apoptosis correlates with active NF- $\mathrm{B}$ expression and disease severity. Once activated, NF- $\kappa \mathrm{B}$ modulates expression of various $\mathrm{Bcl}-2$ family genes as well as Caspase function. In our study, we found that the expression of apoptosis-related proteins, such as Caspase-3 and Bax, was initiated by NF- $\mathrm{kB}$. Downregulation of high levels of Caspase-3 and Bax by oral administration of CBS suggests that the regulation of apoptosis through NF- $\kappa B$ may be a potential mechanism of action for NAFLD therapy.

\section{Conclusion}

In conclusion, we successfully established an NAFLD model by feeding mice a $30 \%$ fructose solution. CBS treatment showed beneficial effects on fructose-induced NAFLD by correcting lipid and glucose metabolic disorders, and by 
suppressing the expression of adipogenic protein. In addition, CBS treatment altered the progression of NAFLD by boosting antioxidant activity and alleviating apoptosis. Although the results of our study are very promising, the material basis of CBS is complicated and further in-depth studies are clearly warranted.

\section{Acknowledgment}

This study was supported by the National Natural Science Foundation of China (grant numbers 81573788 and 81503225).

\section{Author contributions}

Wenxi He is the first author and performed all steps of the experiments. Yanjiao Xu, Jinyu Yang, Juan Li, and Jingli Lu assisted Wenxi He in conducting the experiments. Wenxi He wrote the manuscript. Dong Liu helped in literature survey and study design. All authors contributed toward data analysis, drafting and critically revising the paper, gave final approval of the version to be published, and agree to be accountable for all aspects of the work.

\section{Disclosure}

The authors report no conflicts of interest in this work.

\section{References}

1. Loomba R, Sanyal AJ. The global NAFLD epidemic. Nat Rev Gastroenterol Hepatol. 2013;10(11):686-690.

2. Vernon G, Baranova A, Younossi ZM. Systematic review: the epidemiology and natural history of non-alcoholic fatty liver disease and non-alcoholic steatohepatitis in adults. Aliment Pharmacol Ther. 2011; 34(3):274-285.

3. Abdelmalek MF, Suzuki A, Guy C, et al. Increased fructose consumption is associated with fibrosis severity in patients with nonalcoholic fatty liver disease. Hepatology. 2010;51(6):1961-1971.

4. Chung M, Ma J, Patel K, Berger S, Lau J, Lichtenstein AH. Fructose, high-fructose corn syrup, sucrose, and nonalcoholic fatty liver disease or indexes of liver health: a systematic review and meta-analysis. Am J Clin Nutr. 2014;100(3):833-849.

5. de Ruyter JC, Olthof MR, Seidell JC, Katan MB. A trial of sugar-free or sugar-sweetened beverages and body weight in children. $N$ Engl J Med. 2012;367(15):1397-1406.

6. Zhang LD, Wei W, Sun XH, Song YL, Fen XZ, Jiang M. [Cross-sectional study of Chinese medicine disease, constitution and syndrome of nonalcoholic fatty liver disease]. World Chinese Journal of Digestology. 2015;(33):5296-5302.

7. Chen Q, Wang T, Li J, et al. Effects of Natural Products on FructoseInduced Nonalcoholic Fatty Liver Disease (NAFLD). Nutrients. 2017;9(2):pii:E96.

8. Shizhen Li. Compendium of Materia Medica. 1578.

9. Chen SP. [Research on Calculus bovis]. Zhong Yao Tong Bao. 1987; 12(3):59-61. Chinese.

10. Feng $\mathrm{C}$, Li X, Zhang $\mathrm{C}$, et al. Development of a rapid and simple LC-MS/MS method for identification and quality control of natural Calculus bovis and Calculus bovis sativus. Anal Methods. 2015;7(18): 7606-7617.

11. Chinese Pharmacopoeia Commission. Pharmacopoeia of the People's Republic of China. China: China Medical Science Press; 2015:70-71.
12. Matthews DR, Hosker JP, Rudenski AS, Naylor BA, Treacher DF, Turner RC. Homeostasis model assessment: insulin resistance and betacell function from fasting plasma glucose and insulin concentrations in man. Diabetologia. 1985;28(7):412-419.

13. Wang K. Molecular mechanisms of hepatic apoptosis. Cell Death Dis. 2014;5:e996.

14. Ackerman Z, Oron-Herman M, Grozovski M, et al. Fructose-induced fatty liver disease: hepatic effects of blood pressure and plasma triglyceride reduction. Hypertension. 2005;45(5):1012-1018.

15. Hebbard L, George J. Animal models of nonalcoholic fatty liver disease Nat Rev Gastroenterol Hepatol. 2011;8(1):35-44.

16. Lim JS, Mietus-Snyder M, Valente A, Schwarz JM, Lustig RH. The role of fructose in the pathogenesis of NAFLD and the metabolic syndrome. Nat Rev Gastroenterol Hepatol. 2010;7(5):251-264.

17. Yilmaz Y. Review article: fructose in non-alcoholic fatty liver disease. Aliment Pharmacol Ther. 2012;35(10):1135-1144.

18. Softic S, Cohen DE, Kahn CR. Role of dietary fructose and hepatic de novo lipogenesis in fatty liver disease. Dig Dis Sci. 2016;61(5): 1282-1293.

19. Witkowski A, Rangan VS, Randhawa ZI, Amy CM, Smith S. Structural organization of the multifunctional animal fatty-acid synthase. Eur $J$ Biochem. 1991;198(3):571-579.

20. Dorn C, Riener MO, Kirovski G, et al. Expression of fatty acid synthase in nonalcoholic fatty liver disease. Int J Clin Exp Pathol. 2010; 3(5):505-514.

21. Jaworski K, Sarkadi-Nagy E, Duncan RE, Ahmadian M, Sul HS. Regulation of triglyceride metabolism. IV. Hormonal regulation of lipolysis in adipose tissue. Am J Physiol Gastrointest Liver Physiol. 2007;293(1): G1-G4.

22. Carmen GY, Victor SM. Signalling mechanisms regulating lipolysis. Cell Signal. 2006;18(4):401-408.

23. Rolo AP, Teodoro JS, Palmeira CM. Role of oxidative stress in the pathogenesis of nonalcoholic steatohepatitis. Free Radic Biol Med. 2012; 52(1):59-69.

24. Musso G, Cassader M, Gambino R. Non-alcoholic steatohepatitis: emerging molecular targets and therapeutic strategies. Nat Rev Drug Discov. 2016;15(4):249-274.

25. Wang C, Cui Y, Li C, et al. Nrf2 deletion causes "benign" simple steatosis to develop into nonalcoholic steatohepatitis in mice fed a high-fat diet. Lipids Health Dis. 2013;12:165.

26. Shimozono R, Asaoka Y, Yoshizawa Y, et al. Nrf2 activators attenuate the progression of nonalcoholic steatohepatitis-related fibrosis in a dietary rat model. Mol Pharmacol. 2013;84(1):62-70.

27. Zhong XM, Ren XC, Lou YL, et al. Effects of in-vitro cultured calculus bovis on learning and memory impairments of hyperlipemia vascular dementia rats. J Ethnopharmacol. 2016;192:390-397.

28. Wu T, Chang MJ, Xu YJ, Li XP, Du G, Liu D. Protective effect of Calculus Bovis Sativus on intrahepatic cholestasis in rats induced by alpha-naphthylisothiocyanate. Am J Chin Med. 2013;41(6): 1393-1405.

29. Gazzin S, Vitek L, Watchko J, Shapiro SM, Tiribelli C. A Novel Perspective on the Biology of Bilirubin in Health and Disease. Trends Mol Med. 2016;22(9):758-768.

30. Stocker R, Yamamoto Y, McDonagh AF, Glazer AN, Ames BN. Bilirubin is an antioxidant of possible physiological importance. Science. 1987;235(4792):1043-1046.

31. Kumar R, Rastogi A, Maras JS, Sarin SK. Unconjugated hyperbilirubinemia in patients with non-alcoholic fatty liver disease: a favorable endogenous response. Clin Biochem. 2012;45(3):272-274.

32. Kwak MS, Kim D, Chung GE, et al. Serum bilirubin levels are inversely associated with nonalcoholic fatty liver disease. Clin Mol Hepatol. 2012;18(4):383-390.

33. Jang BK. Elevated serum bilirubin levels are inversely associated with nonalcoholic fatty liver disease. Clin Mol Hepatol. 2012;18(4):357-359.

34. Hinds TJ, Adeosun SO, Alamodi AA, Stec DE. Does bilirubin prevent hepatic steatosis through activation of the PPARalpha nuclear receptor? Med Hypotheses. 2016;95:54-57. 
35. Sokolovic D, Nikolic J, Kocic G, et al. The effect of ursodeoxycholic acid on oxidative stress level and DNase activity in rat liver after bile duct ligation. Drug Chem Toxicol. 2013;36(2):141-148.

36. Gentile CL, Nivala AM, Gonzales JC, et al. Experimental evidence for therapeutic potential of taurine in the treatment of nonalcoholic fatty liver disease. Am J Physiol Regul Integr Comp Physiol. 2011;301(6): R1710-R1722.
37. Ribeiro PS, Cortez-Pinto H, Sola S, et al. Hepatocyte apoptosis, expression of death receptors, and activation of NF-kappaB in the liver of nonalcoholic and alcoholic steatohepatitis patients. Am J Gastroenterol. 2004;99(9):1708-1717.

\section{Publish your work in this journal}

Drug Design, Development and Therapy is an international, peerreviewed open-access journal that spans the spectrum of drug design and development through to clinical applications. Clinical outcomes, patient safety, and programs for the development and effective, safe, and sustained use of medicines are the features of the journal, which has also been accepted for indexing on PubMed Central. The manuscript management system is completely online and includes a very quick and fair peer-review system, which is all easy to use. Visit http://www.dovepress.com/testimonials.php to read real quotes from published authors.

Submit your manuscript here: http://www.dovepress.com/drug-design-development-and-therapy-journal 